\title{
Current Problems of the Criminal-Legal Regulation of Compulsory Treatment in a Psychiatric Hospital in Kazakhstan and Russia
}

\author{
Aigul Turehanovna Ismagulova ${ }^{1}$ \\ ${ }^{1}$ Federal State Institution of Higher Professional Education "Chelyabinsk State University" Kostanai branch, \\ Kazakhstan \\ Correspondence: Aigul Turehanovna Ismagulova, Borodina Street, 168a, Kostanay, 110000, Kazakhstan.
}

\author{
Received: November 26, 2014 Accepted: December 10, 2014 Online Published: March 20, 2015 \\ doi:10.5539/ass.v11n8p32 \\ URL: http://dx.doi.org/10.5539/ass.v11n8p32
}

\begin{abstract}
The present article deals with the problems of criminal-legal regulation of compulsory treatment in a psychiatric hospital under the laws of the Republic of Kazakhstan and the Russian Federation, and offers defined innovations in the existing criminal laws. The author suggests to adopt independent standard and legal acts in Russia and in Kazakhstan, containing set of medical and social criteria of this or that purpose of types of compulsory treatment as the unreasonable tightening of this question is directly reflected in observance of the principles of legality, justice and humanity.
\end{abstract}

Keywords: criminal and legal regulation, criminal law, criminology, crime, offense, detention of the person who has committed a crime, infliction of harm, violence application, right for detention of the criminal, limitation periods, necessary defense, necessary defense, imaginary defense, cash and reality of encroachment, actual mistake

\section{Introduction}

The current mental state of society and the trend of increasing number of dangerous acts committed by persons suffering from mental disorders require adequate response from the government. One of the means for this category of citizens is Institute of compulsory measures of a medical nature that contains a differentiated approach to psychiatric treatment depending on the severity of the mental state of the person, who committed the act, the degree of social danger of such a person, and other objective data A.

According to Article 92 of the Criminal Code of the Republic of Kazakhstan and Article 101 of the Criminal Code of the Russian Federation compulsory treatment in a psychiatric hospital can be carried out, if the nature of mental disorder of the person requires such treatment conditions, care, maintenance and attendance that can only be conducted in a psychiatric hospital.

The Criminal Codes of Kazakhstan and Russia include three types of psychiatric hospitals: psychiatric hospital of general type, psychiatric hospital of specialized type, psychiatric hospital of specialized type with intensive attendance.

The kinds of psychiatric hospitals indicated in the Criminal Law vary according to the criteria of safety control of persons placed there and other people, who are being treated in a psychiatric hospital, under the differences in the mode of maintenance, the degree of intensity of attendance for these individuals.

Neznamova Z. A. believes that the criteria for selecting the type of psychiatric hospital are described by the legislator schematically and as much in general terms, that the choice of the type of hospital treatment based on them is almost impossible. Meanwhile, in accordance with the law, the prescription of the kind of compulsory measure of a medical nature is carried out by the court, although on the recommendation of forensic psychiatric examinations, medical commissions of psychiatric institutions, and psychiatric commissions on inspection of convicted persons. As far as there are no clear criteria for selecting the type of psychiatric hospital in the law, the courts rely almost entirely on solutions of psychiatrists. Meanwhile, in all regulations the decision on the necessity of usage of compulsory measures of a medical nature and the type of hospital is referred to the competence of the court. It is the institution that has sole responsibility for the use of this type of actions under the criminal legal nature. As we consider, the normative criteria for selecting measures of compulsory treatment should be clearer and set in law. 
The court appoints a particular type of compulsory treatment, primarily based on the mental state of a person, the degree of danger to him/herself, others, the possibility of a particular social dangerous act. In particular, this rule applies in respect of persons found mentally incompetent and at the same time because of the characteristics of mental condition or severity of socially dangerous acts that represent a danger to society (legal and medical aspects or criteria). Two of these criteria can be not the same, what is certainly reflected in a set of used tools. According to category of gravity of offence, without regard to mental condition and social danger, the type of establishment and the regime cannot be determined. In such a way, Kondratiev F. V. draws attention to the fact that of all the illegal acts committed by the share of persons with mental disorders account for less than $1 \%$ per cent, and accounted for all persons with mental disorders of patients who committed socially dangerous acts (SDAs) and found mentally incompetent, representing less than $2 \%$. There are such facts, when a person commits systematic crimes, which disappear with the development of mental disorders, and reproduce again in the process of their reduction. This reality poses a difficult problem of the relationship between mental disorder and socially dangerous behavior.

According to paragraph 2 of Article 92 of the Criminal Code of the Republic of Kazakhstan and Part 2 of Article 101 of the Criminal Code of the Russian Federation psychiatric hospital of general type is assigned to a person who is in his mental state in need of hospital treatment and attendance, but does not require intensive attendance.

As noted above, there are no clear medical and social criteria for the prescription of treatment in a psychiatric hospital of general type in the Kazakh and Russian legislation, what creates difficulties of law enforcement.

In Russia, a number of detailing regulations related to the prescription of specific types of psychiatric treatment, contained in subordinate act - in a Methodical letter of Ministry of Healthcare of the Russian Federation dated in July 23, 1999 \# 2510/4817-01-25 (On the procedure for the application of compulsory and other medical measures for persons with severe mental disorders, who committed socially dangerous acts (Article 21 and Paragraph 1 of Article 81 of the Criminal Code of the Russian Federation)", agreed with the Supreme Court, General Prosecutor's Office and the Ministry of Internal Affairs of Russia. In view of the fact, that the present letter contained legal regulations, it (the letter) was canceled by the letter from the Ministry of Healthcare of the Russian Federation dated in May 10, 2001 \# 2510/4817-01-25. Thus, the problem has arisen in the sphere of application of compulsory measures of a medical nature, when still there is no new document meeting modern demands in return of the canceled Methodical letter of Ministry of Healthcare.

In this regard, it is necessary to "get out", as it offers Batanov A. N. in a paper written a few years ago: "At the present time, in our opinion, it is appropriate to use the regulations of the methodical letter as recommendations in the setting of determining the type of compulsory measures."

\section{Main Part}

In accordance with the Methodical letter on an order of usage of compulsory and other measures of a medical nature in respect of persons with severe mental disorders, who committed socially dangerous acts, compulsory treatment in a psychiatric hospital may be prescribed to individuals:

- Committed socially dangerous act, and (or) located at a given time in a psychotic state, in cases of absence of clear tendencies towards gross violations of hospital regime and favorable prognosis with respect to the therapeutic relief of psychosis, but under the persistent likelihood of its recurrence (chronic diseases with frequent relapses, the presence of abnormal ground leading to the emergence of temporary psychotic conditions such as alcoholism, drug addiction, residual organic brain damage, etc.), as well as under the lack of criticism to his/her condition, which makes it impossible to conduct the treatment in a hospital or in the outpatient setting on a general basis;

- With signs of dementia, mental defect states of different origin and other mental disorders, who have committed acts provoked by some external adverse circumstances, without a clear tendency towards repetition and gross violations of hospital regime;

- Suffering from temporary mental disorder developed after committing socially dangerous act, but before sentencing (compulsory treatment before the release of the defined disease state), with no clear tendency to commit new socially dangerous acts and gross violations of hospital regime;

- With chronic mental disorders or dementia after compulsory treatment in a psychiatric hospital of specialized type, including intensive attendance, in case of improvement of their mental state and (or) reduction of danger allowing to continue compulsory treatment in a psychiatric hospital of general type;

- Discovered deterioration of mental state and (or) increase of danger during earlier court-appointed outpatient treatment, if it makes it impossible to conduct treatment and rehabilitation measures in an outpatient setting and 
requires their transfer to a hospital of general type.

Compulsory treatment in a psychiatric hospital of specialized type may be prescribed to a person, which requires constant attendance according to his/her mental condition.

In fact, these arguments are based on the regulations of the law on psychiatric care.

It is fixed in it that persons characterized by heightened aggression and tend to trespass to the person, should be kept separate and have a special regime.

There are relatively a few persons, among patients admitted for compulsory treatment, which fell ill for the first time or recently. Experts say that most often it is referred to long-term ill, often repeatedly treated with no visible effect, especially in various psychiatric hospitals.

The following are the recommendations on use to put in hospitals of specialized type:

- Persons with chronic mental disorders or dementia, detecting liability to repeated socially dangerous acts and violations of hospital regime by virtue of the clinical manifestations and (or) premorbid personality traits, making it impossible to conduct medical and rehabilitation measures in a hospital of general type;

- Persons suffering from temporary mental disorder developed after committing socially dangerous act, but before sentencing (compulsory treatment before the release from a disease state), in the case when they are a thread of making new socially dangerous acts, gross violations of hospital treatment, including escape;

- Persons with mental disorders or dementia after compulsory treatment in a hospital of specialized type with intensive attendance in case of improvement of their mental state and (or) reduction of danger allowing to continue compulsory treatment in a hospital of specialized type (in order of changing the compulsory measure of a medical nature);

- Persons discovered deterioration of mental state and (or) increase of danger during earlier court-appointed less strict compulsory measure of a medical character, if it makes it impossible to conduct treatment and rehabilitation measures in the former conditions and requires their transfer to a hospital of specialized type (in order of changing the compulsory measure of a medical nature).

In such a way, a psychiatric hospital of a specialized type is designed for persons, who are in need of hospital treatment and constant attendance according to their mental state, in addition characterized by proneness to conflict in relation to the medical staff, his/her liability to commit serious crimes, escapes, and aggressiveness.

Persons committed socially dangerous acts, but found insane are maintained in psychiatric hospitals of specialized type. As noted by psychiatrists, individual approach to each patient and, as may be necessary derogation in the form of physical restraint and isolation is supposed for such cases.

On the basis of individual approach, which includes prediction of the behavior of patient, psychiatrist independently defines terms of application of physical restraint and isolation measures, what is noted in the medical records. In terms of records specialists operate on the concept of "standardization", which means - the creation of uniform requirements for the prevention, diagnosis, treatment and psychosocial rehabilitation of patients with mental disorders receiving compulsory medical treatment, for the conditions of their maintenance and quality criteria of the conducted treatment, which is accompanied by keeping the relevant protocols.

The psychiatric hospital of specialized type with intensive attendance is defined by the legislator according to strictness in the following way, which is in accordance with the Methodical letter appropriate to apply in respect of persons:

- With chronic mental illness or dementia, showing a tendency caused by the clinical manifestations and (or) premorbid personality traits to commit repeated serious or of a particularly serious nature socially dangerous acts, especially of a violent nature;

- With chronic mental disorders or dementia, defining persistent anti-social tendencies by virtue of clinical manifestations and (or) premorbid personality traits, manifested in multiple socially dangerous acts, as well as gross violations of hospital regime according to previous hospitalization data (attacks against staff, escapes, initiation of group violence), if the noted violations make it impossible to conduct medical and rehabilitation measures under the conditions of use of other compulsory measures of a medical nature;

- Suffering from temporary mental disorder developed after committing socially dangerous act, but before sentencing (compulsory treatment before the release from a disease state), in case when they are a threat of committing new serious or of a particularly serious nature acts, as well as escape;

- Discovered deterioration of their mental state and (or) increase of danger during the previously court-appointed 
less strict compulsory measure of a medical nature, if it makes it impossible to conduct treatment and rehabilitation measures in the former conditions and requires their transfer to a hospital of specialized type with intensive attendance (in order of changing the compulsory measure of a medical nature).

Compulsory treatment in a psychiatric hospital of specialized type with intensive attendance is prescribed to persons who are in their mental state represent an increased danger for themselves and others and require constant intensive attendance. Criteria for the prescription of a particular type of compulsory treatment are based on differences of regimes of in the content of patients, varied rehabilitation activities, and other features of hospitals of different types.

Generally, these are persons who committed serious and high crimes, or repeatedly committed socially dangerous acts, and their mental state is characterized by mental disorders. Special security departments are organized in these hospitals not only for the exterior guard of hospitals, but also for watching the behavior of the persons indoors with the use of alarm and additional monitoring systems.

An important criterion for compulsory treatment in psychiatric hospitals of specialized type with intensive attendance is the severity of the committed act. Then there are the combination of the severity of the mental state and the severity of the dangerous action and severity of mental states at any socially dangerous act.

The severity of the committed socially dangerous act, first of all, refers to the social indications for the prescription of compulsory treatment in psychiatric hospitals with intensive attendance. Then follows the repetition of socially dangerous acts, usually in such cases the previous compulsory treatment is ineffective. The reason for this is, in a number of cases, heavy criminal history and the difficulties of maintenance of patients in hospitals of general type caused by the constant aggression against staff. Head of the 4th department of Pavlodar neuropsychiatric clinic, psychiatrist A. Lobodenko, considers also in this way: "Speaking of recovery guarantees of mentally ill people, according to the American Psychiatric Association, relapse is observed in 50\% of persons who had undergone compulsory treatment. Unfortunately, there is no medicine in the world, which ensure patients from their diseases. Especially from schizophrenia. Therefore, the duration of their treatment in hospital conditions should be as long as possible, in order to protect society from the mentally ill citizens".

Analysis of the criminal legislations of foreign countries shows that differentiation of psychiatric institutions is carried out in some criminal laws (the Criminal Code of Moldova, the Criminal Code of Estonia, the Criminal Code of Armenia), in others merely states the general view of psychiatric institutions (the Criminal Code of Poland) the Criminal Code of Japan) or a psychiatric hospital (the Criminal Code of Germany).

In this way, it may be noted that at the moment there are the gaps in relation to the detailed normative regulation of types of compulsory measures of a medical nature despite the relative differentiation of compulsory psychiatric treatment in the criminal laws of Kazakhstan and Russia. National legislation on psychiatry did not have precedents of creating regulations clearly defining criteria for the prescription of a particular type of compulsory measures of a medical nature. There is still no worth alternative in the Russian Federation in return for Methodical letter of the Ministry of Healthcare "On the procedure for the application of compulsory and other medical measures for persons with severe mental disorders, who committed socially dangerous acts" which became invalid.

\section{Conclusion}

From our point of view, it is necessary to adopt an independent regulatory legal act in the Republic of Kazakhstan and the Russian Federation, containing a set of medical and social criteria for the prescription of a particular type of compulsory treatment as unreasonable delay in this matter is directly reflected on the observance of the principles of legitimacy, justice and humanism.

\section{References}

A Methodical Letter of Ministry of Healthcare of the Russian Federation. (1999). On the procedure for the application of compulsory and other medical measures for persons with severe mental disorders, who committed socially dangerous acts (Article 21 and Paragraph 1 of Article 81 of the Criminal Code of the Russian Federation) of the Russian Federation "A Methodical Letter of Ministry of Healthcare of the Russian Federation dated in July 23, 1999 \# 2510/4817-01-25. On the procedure for the application of compulsory and other medical measures for persons with severe mental disorders, who committed socially dangerous acts (Article 21 and Paragraph 1 of Article 81 of the Criminal Code of the Russian Federation)" of dated in July 23, 1999 \# 2510/4817-01-25, 180.

Batanov, A. (2004). Compulsory measures of a medical nature (history, theory, legislative regulation and practice of use) (p. 189). PhD thesis, Ulyanovsk State University, Ulianovsk. 
Bukreeva, N., \& Merzlikin, A. (2006). Problems of the organization of compulsory treatment of patients with mental disorders in terms of health care reform. Rossiyskiy psikhiatricheskiy zhurnal, 4, 84.

Bulygina, V. (2006). Psychosocial rehabilitation goals during compulsory treatment in a psychiatric hospital. Rossiyskiy psikhiatricheskiy zhurnal, 2, 23.

Dzhusupgaliyeva, A., \& Nesipbayev, S. (2003). Choose the type of compulsory treatment. Mir zakona, 6, 34.

Golyshkin, V. (2007). I bore you, I'll kill you: Slaughtering her husband, she continued with impunity to threaten his mother and her son. Juridicheskaya gazeta, the first of November 167, 4.

Kondratyev, F. (2006). Problematic aspects of social danger of persons with mental disorders. Rossiyskiy psikhiatricheskiy zhurnal, the journal, 3, 64 .

Kozachenko, I. (2013). Ugolovnoye pravo. Overview (Obshchaya chast): Textbook (p. 705). Moscow, NORMA.

Law of the Armenia "The Criminal Code of of the Republic of Armenia" of 04.18.2003 Volume 3P-528, 190. Retrieved September 5, 2013, from http://www. parliament.am/

Law of the Estonia "The Criminal Code of Estonia" of 6.06.2001 Volume EE133, 200. Retrieved September 4, 2013, from http://www.wipo.int

Law of the Federal Republic of Germany "The Criminal Code of Federal Republic of Germany" of 13 November 1998, 260. Retrieved September 6, 2013, from http://www.gesetze-im

Law of the Japan "Crimes Committed within Japan" of April 24, 1907 Volume Act No, 45. Retrieved September 5, 2013, from http://www.japaneselawtranslation.go.jp

Law of the Moldova "Penal Code of Moldova" of 04.18.2002 Volume \# 985-XV, 230. Retrieved September 4, 2013, from http://www.nyulawglobal.org

Law of the Poland "The Criminal Code of Poland" of 06 June 1997.Volume 476, 233. Retrieved September 5, 2013, from http://www.legislationline.org/

Zharikov, N. (2006). Sudebnaya psikhiatriya textbook for high schools (p. 670). Moscow: Norma.

Zhokov, D. (2011). Modern Humanitarian Academy Problems of legal regulation of criminal responsibility for crimes against minors. "Law and Security", the journal, 2(39), 44.

\section{Copyrights}

Copyright for this article is retained by the author(s), with first publication rights granted to the journal.

This is an open-access article distributed under the terms and conditions of the Creative Commons Attribution license (http://creativecommons.org/licenses/by/3.0/). 